\title{
Impact of the Meningococcal A Conjugate Vaccine Introduction in the African Meningitis Belt, 2010-2017
}

\author{
Andre Arsene Bita Fouda \\ College of Health Sciences, Walden University, Minneapolis, USA \\ Email address: \\ bitaandre@yahoo.fr \\ To cite this article: \\ Andre Arsene Bita Fouda. Impact of the Meningococcal A Conjugate Vaccine Introduction in the African Meningitis Belt, 2010-2017. \\ American Journal of Biomedical and Life Sciences. Vol. 7, No. 4, 2019, pp. 84-92. doi: 10.11648/j.ajbls.20190704.13
}

Received: July 8, 2019; Accepted: July 30, 2019; Published: August 16, 2019

\begin{abstract}
Meningococcal meningitis remains a burden in the African meningitis belt. Before 2010, Neisseria meningitidis serogroup A ( $N$. meningitidis A) was the predominant pathogen causing deathly epidemics. The meningococcal A conjugate vaccine (MACV, MenAfrivac ${ }^{\circledR}$ ) protects against $N$. meningitidis A. It was introduced in 2010 into highest meningitis risk health districts. There was limited data on the effects of MACV, mainly on the degree of relationship between $N$. meningitidis $\mathrm{A}$ and the MACV immunization coverage. The purpose of this quantitative study was to assess the effectiveness of MACV from 2010 to 2017 in 21 out of 26 countries of the African meningitis belt. An interrupted time series design and nonprobability sampling were used. Secondary data issued from meningitis enhanced surveillance were retrieved from World Health Organization database. The social ecological model was used as a theoretical framework for this study. The binomial negative regression and Pearson's Chi-Square tests were used. The study found that after the MACV introduction there were a high degree of relationship between $N$. meningitidis A and MACV immunization coverage $\left(\chi^{2}(1)=11039.49, p=0.000\right.$, Phi $=$ $0.657, \mathrm{P}=0.000$ ), $99 \%$ decline of the risk of $N$. meningitidis A (RR 0.01, 95\% CI 0.08-0.013), and 99.6\% decline of risk of epidemic due to $N$. meningitidis A (RR $0.004,95 \%$ CI $0.001-0.016$ ). The study demonstrated that high MACV coverage and high-quality meningitis surveillance were pivotal to reduce the burden of meningococcal meningitis A epidemic in African meningitis belt. Based on the results of this study, it is recommended to development and manufacture an affordable multivalent polysaccharide conjugate vaccine against $N$. meningitis $(\mathrm{A}, \mathrm{C}, \mathrm{W} 135, \mathrm{X}, \mathrm{Y})$ and introduce in meningitis belt countries to eliminate meningococcal meningitis in Africa, to update the risk assessment of the meningitis status of Africa meningitis belt after the introduction of MenAfriVac ${ }^{\circledR}$, to continue to improve meningitis enhanced surveillance, and improving public health policies on immunization and meningitis enhanced surveillance to ensure sustainable high immunization coverage of meningococcal vaccines and high quality of meningitis epidemic detection.
\end{abstract}

Keywords: Meningococcal Meningitis A, Epidemic, Meningococcal a Conjugate Vaccine, African Meningitis Belt, Neisseria Meningitidis A

\section{Introduction}

Meningococcal meningitis is a major public health problem in the 26 countries of the African meningitis belt stretching from Senegal in the west to Ethiopia in the east, where an estimated 430 million people are living [1-5]. Meningococcal meningitis cases occur throughout the world. The findings showed that meningococcal meningitis has the greatest incidence with large epidemics in Africa in the dry season [6-8]. During epidemics, the incidence can approach 1,000 per 100,000 , or $1 \%$ of the population. Repeated pandemics of Neisseria meningitidis A (N. meningitidis A) disease have taken place in Sahelian and sub-Sahelian countries of Africa, known as the African meningitis belt, every 5-10 years since 1905 [9, 10, 12]. Before the introduction of Meningococcal A Conjugate Vaccine (MACV) in 2010, N. meningitidis A accounted for an estimated 90 percent of all cases in the African meningitis belt, with epidemics occurring at intervals of 7-14 years [2, 11-15].

The meningococcal meningitis is a bacterial form of meningitis, a serious infection of the meninges, thin fibrous tissue that covers the brain and spinal cord. Of the 12 serogroups of N. meningitidis identified, four serogroups, A, 
$\mathrm{B}, \mathrm{C}$, and $\mathrm{W} 135$, are recognized to be the main causes of epidemics. N. meningitidis is transmitted from person-toperson through droplets of respiratory or throat secretions from carriers. Ten percent to $25 \%$ of the population carries $N$. meningitidis in their throat at any given time. It can cause severe brain damage and is fatal in $50 \%$ of cases if left untreated $[1,2,10]$.

The largest meningococcal meningitis epidemic was reported in 1996 and 1997, where more than 25,000 people died and more than 250,000 were affected. Following this devastating epidemic, African leaders called for the development of an affordable vaccine that would eliminate $N$. meningitidis A epidemics in Africa. Then, this affordable vaccine so-called MACV or MenAfriVac ${ }^{\circledR}$ was developed by Serum Institute of India and prequalified in 2009 by WHO. MACV is being introduced in the African meningitis belt countries since 2010 to eliminate meningococcal meningitis caused by $N$. meningitidis A. MACV was introduced firstly in Burkina Faso [3, 11-14, 16-22]. Only the health districts that are at highest risk were selected to introduce MenAfriVac $^{\circledR}$. The selection was made through the risk assessment using the district prioritization tool developed by WHO [15, 23].

Between 2010 and 2017, 21 countries have introduced MACV with more than 280 million people vaccinated aged 1 to 29 years through vaccination mass campaigns [1].

The reduction of the incidence and occurrence of meningitis epidemics caused by $N$. meningitidis $\mathrm{A}$ in the meningitis belt were demonstrated by some authors [24-44]. Findings also showed the signifcant reduction of $\mathrm{NmA}$ carriage and then the herd immunity provided by MACV [3, $26,43,44]$ Especially, Novak et al. showed $71 \%$ decline in risk of meningitis (suspected cases) and $>99 \%$ decline in risk of $N$. meningitidis A (confirmed cases) in Burkina Faso 1 year after the introduction of MACV [25]. Daugla et al. (2013) found a 94\% reduction in the incidence of meningitis in a vaccinated population and $98 \%$ decrease in $N$. meningitidis A carriage prevalence within 4-6 months after MACV mass vaccination campaign [26]. A study conducted by Trotter et al. found in nine countries (Benin, Burkina Faso, Chad, Côte d'Ivoire, Ghana, Mali, Niger, Nigeria, Togo) a $58 \%$ decline in incidence of meningitis (suspected cases), $>99 \%$ decline in incidence of $N$. meningitidis A (confirmed cases), and $60 \%$ decline in epidemics risk of a district reaching the epidemic threshold [27]. Kristiansen et al. found the effectiveness of MACV on the carriage of $N$. meningitidis A among persons vaccinated in Burkina Faso 2 years after a MACV mass vaccination campaign [28].

This study considered 21 out of 26 of meningitis belt countries. Meningitis surveillance has been enhanced since 2002 in the African meningitis belt countries. In preparation for the introduction of MACV an enhanced meningitis surveillance network was established by WHO since 2002 . Meningitis enhanced surveillance aims to assess the effects of the introduction of new vaccines, to detect and confirm epidemics and launch appropriate response strategies, to assess case burden and incidence trends, to monitor the antibiotic resistance profile of $N$. meningitidis, including $N$. meningitidis A or other pathogens, and to monitor the circulation, distribution, and evolution of $N$. meningitidis serogroups and other pathogens. It helps not only to detect epidemics earlier but also to control the elimination of disease [45-49].

The purpose of this study was to assess the effectiveness of the introduction of MACV in the 21 out of 26 countries of the African meningitis belt. Studying effects including protection more years and more countries after 2010 than the previous study was relevant and therefore contributed to reduce the gap in the literature on the effects of MACV. The potential positive social change is the reinforcement of public health policies, especially on surveillance and immunization, to achieve the elimination of vaccine-preventable diseases. The high level of MACV coverage and the high quality of meningitis enhanced surveillance might be two relevant factors in achieving the elimination of $N$. meningitidis A. In addressing and emphasizing these factors; sought in this study to create a positive social change with the strengthening of immunization and surveillance policies.

\section{Methods}

\subsection{Study and Research Design}

The study was quasi-experimental, retrospective, and quantitative. The research design was an interrupted time series.

\subsection{Population}

The population of this study was characterized by people living in 1,713 out of 3,817 health districts at highest risk for meningitis in 21 countries of the African meningitis belt. Health districts at highest risk for meningitis were selected to introduce MenAfriVac $\AA$. The selection was made through risk assessment using the district prioritization tool developed by WHO [15, 23]. The 21 countries that were participants of this study were Mali, Burkina Faso, Cameroon, Central Africa Republic, Chad, Benin, Cote d'Ivoire, Togo, Mauritania, Niger, Nigeria, Ghana, Gambia, Guinea, Guinea Bissau, Ethiopia, Sudan, South Sudan, Senegal, and Uganda. The total estimated population was $407,958,506$ persons. People who were vaccinated with MenAfriVac ${ }^{\circledR}$ were aged 1-29 years old because they were the highest risk of meningitis infection caused by $N$. meningitidis A. The age group 1-29 years old represented almost $70 \%$ of the total population. The estimated target population for MenAfriVac $\AA$ vaccination was 285,570,957 people. Figure 1 and Table 1 show that between 2010 and 2017, 286,995,073 were immunized with MenAfriVac $\AA$, thus there was $100 \%$ administrative coverage for the 21 countries of the study, le lowest coverage was reported in Central Africa Republic (88\%). Djingarey et al. found that random survey coverage rates ranged between $69 \%$ to $96 \%$ [50]. The target population of this study was large and representative. Therefore, the findings can be generalized. 


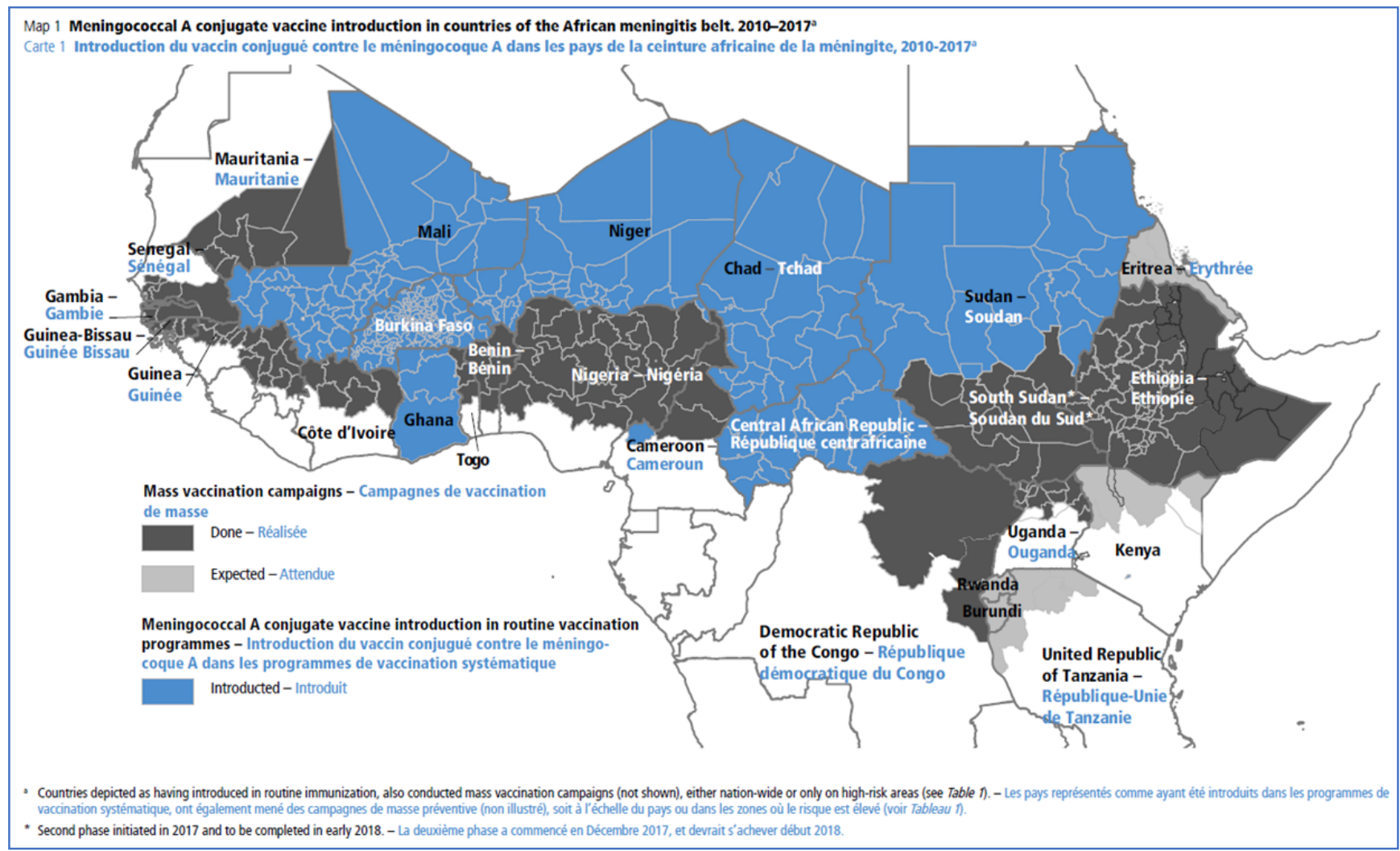

Figure 1. African Meningitis Belt and MenAfriVac ${ }^{\circledR}$ Roll-out 2010-17. (Source WHO).

Table 1. People Vaccinated With MACV 2010-17.

\begin{tabular}{|c|c|c|c|c|c|c|}
\hline Countries & $\begin{array}{l}\text { Total } \\
\text { population } \\
2017 \text { at } \\
\text { meningitis risk }\end{array}$ & $\begin{array}{l}\text { Health districts at } \\
\text { high risk covered by } \\
\text { MenAfriVac } \\
\text { vaccination campaign }\end{array}$ & $\begin{array}{l}\text { Years of } \\
\text { introduction }\end{array}$ & $\begin{array}{l}\text { The target population } \\
\text { for MenAfriVac } \\
\text { vaccination } \\
\text { campaigns }\end{array}$ & $\begin{array}{l}\text { Persons } \\
\text { vaccinated }\end{array}$ & $\begin{array}{l}\text { Administrative } \\
\text { coverage }\end{array}$ \\
\hline Benin & 3708077 & 33 & 2013 & 2595654 & 2718459 & $105 \%$ \\
\hline Burkina Faso & 21557784 & 63 & 2010,2016 & 15090449 & 15295276 & $101.35 \%$ \\
\hline Cameroon & 8751220 & 70 & 2011-12 & 6125854 & 6510729 & $112.80 \%$ \\
\hline Central African Republic & 5226069 & 30 & 2017 & 3658248 & 3220358 & $88.24 \%$ \\
\hline Chad & 13177019 & 99 & 2011-12 & 9223913 & 8732151 & 95 \\
\hline Cote d'Ivoire & 3244287 & 42 & 2014 & 2271001 & 2764839 & $100.40 \%$ \\
\hline $\begin{array}{l}\text { Democratic Republic of } \\
\text { Congo }\end{array}$ & 26008263 & 149 & 2016 & 18205784 & 18058535 & $99.20 \%$ \\
\hline Ethiopia & 88330603 & 102 & 2013-15 & 61831422 & 60996186 & $98.64 \%$ \\
\hline Gambia & 1682750 & 7 & 2013 & 1177925 & 1228419 & $104 \%$ \\
\hline Ghana & 5395356 & 49 & 2012, 2016 & 3776749 & 3705081 & $98.10 \%$ \\
\hline Guinea & 3657747 & 15 & 2015 & 2560423 & 2442566 & $95.40 \%$ \\
\hline Guinea Bissau & 1821931 & 11 & 2016 & 1275352 & 1150136 & $90.10 \%$ \\
\hline Mali & 20260730 & 60 & 2010,20112016 & 14182511 & 14593475 & $102.89 \%$ \\
\hline Mauritania & 2300747 & 33 & 2014 & 1610523 & 1561720 & $97 \%$ \\
\hline Niger & 15529739 & 42 & 2010 & 10870817 & 10575365 & $95.70 \%$ \\
\hline Nigeria & 118680713 & 571 & 2011-14 & 83076499 & 87062324 & $104.79 \%$ \\
\hline Senegal & 6261793 & 35 & 2012 & 4383255 & 4216691 & $96.20 \%$ \\
\hline South Sudan & 6246709 & 47 & 2016 & 4372696 & 4023659 & $92 \%$ \\
\hline Sudan & 42176594 & 188 & 2012-13 & 29523616 & 28232735 & $95.62 \%$ \\
\hline Togo & 3934556 & 28 & 2014 & 2754189 & 2764839 & $102.20 \%$ \\
\hline Uganda & 10005820 & 39 & 2017 & 7004074 & 7141530 & $102 \%$ \\
\hline Total & 407958506 & 1713 & $2010-17$ & 285570954 & 286995073 & $100.49 \%$ \\
\hline
\end{tabular}

Note. Source WHO.

\subsection{Data Collection and Instrumentation}

The secondary data of this study were retrieved between
February 10 and February 28, 2018, from WHO ISTWA databases and $\mathrm{WHO}$ websites and there were accurate. These data concerned meningitis surveillance between 2004 and 
2017 and MACV introduction from 2010 to 2017. The secondary data from meningitis surveillance concerned especially meningitis suspected cases that fit the case definition, CFR, CSF samples tested in laboratories, and the meningitis epidemics due to $N$. meningitidis A reported by health districts using meningitis epidemic threshold. Concerning the MACV introduction, information gathered mainly concerned vaccination coverage, the quality of implementation and evaluation of mass vaccination campaigns, and routine immunization programmes. The data retrieved were aggregated and sent by countries on a regular basis. Data were sent on a weekly basis concerning meningitis surveillance, and monthly regarding MACV immunization activities. The data collected were prior treated, consolidated, harmonized, and validated at the country level before sending to WHO ISTWA. The dataset was created for this study so-called MenA_dataset. They were no discrepancies in data collection. Almost $2.5 \%$ of data were missing because few countries didn't share the data with WHO IST WA. The dependent variables selected were the occurrence of $N$. meningitidis A, laboratory-confirmed or not, meningitis suspected cases, CFR, deaths, and occurrence of meningitis epidemics due to $N$. meningitidis A as reported by health districts. The independent variable was MACV vaccination status of people living in health districts (vaccinated after the introduction of MACV; vaccinated with any other polysaccharide vaccine that includes antigen $A$; unvaccinated before the introduction of MACV). The distribution was a Poisson distribution, where the mean and variance differ from one another. In this study, observations were independent variables. The statistical assumptions for Pearson's Chi-Square were met because the observations for the two-way contingency table analysis were independent of each other, and all the expected occurrences of the crosstab were greater than five. The measuring instrument used in this study was meningitis enhanced surveillance. Enhanced surveillance can be used to evaluate the effects of the introduction of a new vaccine such as MACV.

\subsection{Data Analysis and Statistical Tests}

The inferential statistics were used to respond to the research questions. The first research question contributed to to establish the degree of relationship between $N$. meningitidis A confirmed and the MenAfriVac $₫$ immunization coverage. The Pearson's chi-square was used to determine the degree of the relationship between $N$. meningitidis A confirmed and the MenAfriVac $\AA$ immunization coverage within 21 out of the 26 countries of African meningitis belt between 2010 and 2017 . The second research question contributed to establish the difference of meningitis epidemics caused by $N$. meningitidis A before and after the introduction of MenAfriVac $\AA$. The Pearson's chi-square was used to estimate the relative risk of districts to be in epidemic after the introduction of MenAfriVac $\AA$. Descriptive and inferential statistics were conducted in this study using SPSS 21 version and Microsoft Excel 2013. Before conducting inferential statistics, cleaning data was done for all research questions. A codebook created contain variable names, variable labels, value labels, and a list of any changes.

To test the two hypotheses, descriptive and inferential statistics were chosen. The relative risk was calculated using Pearson's chi-square to determine the degree of relationship between the incidence of $N$. meningitidis A confirmed and the MenAfriVac ${ }^{\circledR}$ immunization coverage, and the occurrence of health districts that reported epidemic due to $\mathrm{N}$. meningitidis A before and after the introduction of

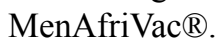

\section{Results}

\subsection{Incidence of $N$. Meningitidis $A$}

The figure 2 shows that between 2004 and 2017 the incidence $N$. meningitidis A confirmed cases reported declined significantly after 2010 with the introduction of MACV. The highest incidence of $N$. meningitidis A was 2066 reported in 2009. Whereas, the lowest incidence was 2 reported in 2017.

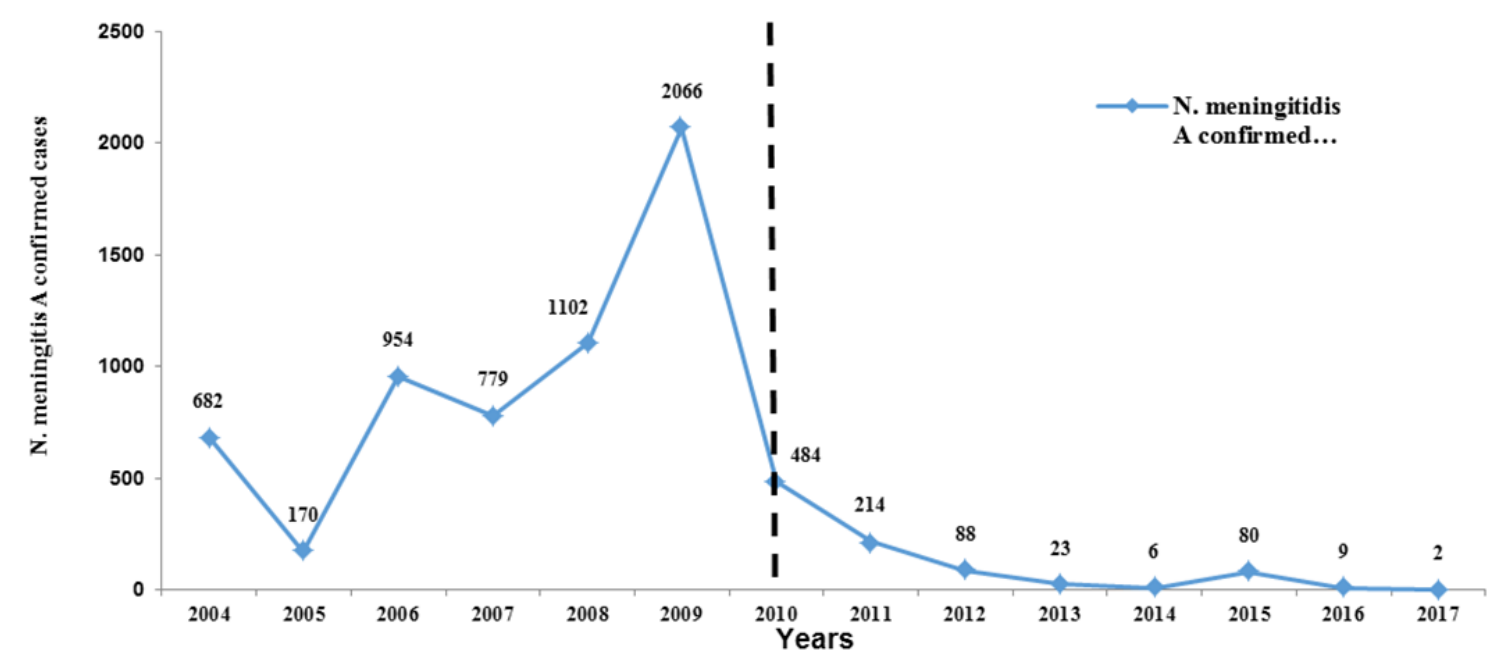

Figure 2. N. meningitidis A confirmed 2004-2017. 
The figure 3 shows the decline of $N$. meningitidis A since 2010 and the predominance of other pathogens as $S$. Pneumoniae, $N$. meningitidis $\mathrm{W} 135$, and $N$. meningitidis $\mathrm{C}$.

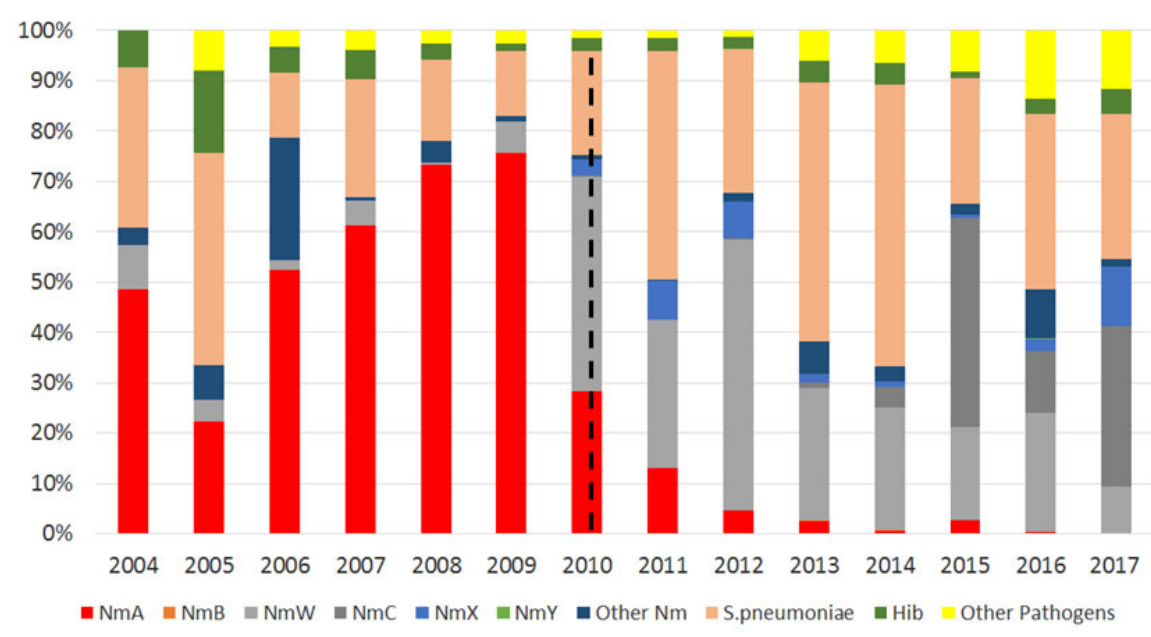

Figure 3. Meningitis pathogens laboratory confirmed 2004-2017.

\subsection{Relationship Between the Incidence of Neisseria Meningitidis Serogroup A and the MenAfriVac ${ }^{\circledR}$ Immunization in 21 Out of the 26 Countries of African Meningitis Belt Between 2010 and 2017}

Table 2 shows that there was a relationship between the incidence of Neisseria meningitidis serogroup A and the MenAfriVac ${ }^{\circledR}$ immunization in 21 out of the 26 countries of African meningitis belt between 2010 and $2017\left(\chi^{2}(1)=11039.49\right.$, $\mathrm{p}=0.000)$.

Table 2. Chi-Square Tests for MenAfriVac ${ }^{\circledR}$ Introduction and N. Meningitidis A.

\begin{tabular}{lllll}
\hline & Value & df & Asymp. Sig. (2-sided) & Exact Sig. (2-sided) \\
\hline Pearson Chi-Square & 11039.4940 & 1 & 000 & Exact Sig.(1-sided) \\
Continuity Correctionb & 11036.477 & 1 & 000 & 000 \\
Likelihood Ratio & 13096.370 & 1 & 000 & 000 \\
Fisher's Exact Tests & & & & 000 \\
N of Valid Cases & 25596 & & & \\
\hline
\end{tabular}

a. 0 cells $(0.0 \%)$ have expected count less than 5 . The minimum expected count is 2501.37 . b. Computed only for a $2 \times 2$ table

The table 3 shows that the relationship is high between the incidence of Neisseria meningitidis serogroup A and the MenAfriVac ${ }^{\circledR}$ immunization in 21 out of the 26 countries of African meningitis belt between 2010 and 2017 (Phi $=0.657$,
$\mathrm{P}=0.000)$. Table 4 shows $99 \%$ decline of risk to report $N$. meningitidis A after the introduction of MenAfriVac ${ }^{\circledR}$ (RR $0.01,95 \%$ CI 0.08-0.013).

Table 3. Symmetry Measures for MenAfriVac ${ }^{\circledR}$ Introduction and $N$. Meningitidis A.

\begin{tabular}{llll}
\hline & & Value & Approx. Sig \\
\hline & Phi & 657 & 000 \\
Nominal by Nominal & Cramer's V & 657 & 000 \\
& Contingency Coefficient & 549 & 000 \\
N of Valid Cases & & 25596 & 25596 \\
\hline
\end{tabular}

The table 4 shows $99 \%$ decline of risk to report $N$. meningitidis A after the introduction of MenAfriVac ${ }^{\circledR}$ (RR $0.01,95 \%$ CI 0.08-0.013).

Table 4. Risk Estimate for MenAfriVac ${ }^{\circledR}$ Introduction and N. Meningitidis A.

\begin{tabular}{|c|c|c|c|}
\hline & \multirow{2}{*}{ Value } & \multicolumn{2}{|c|}{ 95\% Confidence Interval } \\
\hline & & Lower & Upper \\
\hline Odds Ratio for Factor (After MenAfriVac ${ }^{\mathbb{2}}$ introduction / Before MenAfriVac ${ }^{\text {(E) }}$ introduction) & 233.625 & 188.598 & 289.401 \\
\hline For cohort $N$. meningitidis $\mathrm{A}=\mathrm{No}$ & 2.406 & 2.353 & 2.460 \\
\hline For cohort $N$. meningitidis $\mathrm{A}=$ Yes & .010 & .008 & .013 \\
\hline $\mathrm{N}$ of Valid Cases & 25596 & & \\
\hline
\end{tabular}




\subsection{Relationship Between the Occurence of Neisseria Meningitidis Serogroup a Epidemics and the Menafrivac ${ }^{\circledR}$ Immunization in 21 Out of the 26 Countries of African Meningitis Belt Between 2010 and 2017}

The table 5 shows that there was a difference in the frequency of meningitis epidemics caused by Neisseria meningitidis A before and after the MenAfriVac ${ }^{\circledR}$ introduction in 21 out of the 26 countries of African meningitis belt $\left(\chi^{2}(1)=595.351, p=\right.$ $0.000)$.

Table 5. Chi-Square Tests for MenAfriVac ${ }^{\circledR}$ Introduction and District in N. Meningitis A Epidemics.

\begin{tabular}{lllll}
\hline & Value & df & Asymp. Sig. (2-sided) & Exact Sig. (2-sided) \\
\hline Pearson Chi-Square & $595.351 \mathrm{a}$ & 1 & .000 & Exact Sig.(1-sided) \\
Continuity Correctionb & 593.019 & 1 & .000 & .000 \\
Likelihood Ratio & 776.149 & 1 & & .000 \\
Fisher's Exact Tests & & & & .000 \\
N of Valid Cases & 3426 & & & \\
\hline
\end{tabular}

a. 0 cells $(0.0 \%)$ have expected count less than 5 . The minimum expected count is 257.50 . b. Computed only for a $2 \times 2$ table

The table 6 shows $99.6 \%$ decline of risk for a health district to be in epidemic due to $N$. meningitidis A after the introduction of MenAfriVac ${ }^{\circledR}$ (RR 0.004, 95\% CI 0.001-0.016).

Table 6. Risk Estimate for MenAfriVac ${ }^{\circledR}$ Introduction and District in N. Meningitis A Epidemics.

\begin{tabular}{|c|c|c|c|}
\hline & \multirow{2}{*}{ Value } & \multicolumn{2}{|c|}{ 95\% Confidence Interval } \\
\hline & & Lower & Upper \\
\hline Odds Ratio for Factor (After MenAfriVac ${ }^{\circledR}$ introduction / Before MenAfriVac ${ }^{\circledR}$ introduction) & 364.709 & 90.789 & 1465.084 \\
\hline For cohort district in N. meningitis A Epidemics $=$ No & 1.425 & 1.381 & 1.469 \\
\hline $\mathrm{N}$ of Valid Cases & 3426 & & \\
\hline
\end{tabular}

\section{Discussion}

\subsection{The Relationship Between the N. Meningitidis a Reported and the MenAfriVac ${ }^{\circledR}$ Immunization in 21 Out of the 26 Countries of the African Meningitis Belt}

This study found a high degree of relationship between $N$. meningitidis A reported and the MenAfriVac ${ }^{\circledR}$ immunization between 2010 and 2017 in 21 out of the 26 countries of the African meningitis belt, $\left(\chi^{2}(1)=11039.49, \mathrm{p}=0.000\right.$, Phi $=$ $0.657, \mathrm{P}=0.000$ ). The study also found $99 \%$ decline in the risk of $N$. meningitidis A after the introduction of MenAfriVac $^{\circledR}$ (RR 0.01, 95\% CI 0.08-0.013). These results globally confirmed the findings of the literature. The findings showed the relationship between the reduction of $N$. meningitidis A reported and the MenAfriVac ${ }^{\circledR}$ immunization in African meningitis belt countries [1, 12- 25, 37]. The findings in the literature did not assess the strength of the relationship between $N$. meningitidis A reported and the MenAfriVac ${ }^{\circledR}$ immunization in African meningitis belt. The extended finding of this study was the high degree of relationship between the reduction of $N$. meningitidis A reported and the MenAfriVac ${ }^{\circledR}$ immunization in 21 out of the 26 countries of African meningitis belt ( $\mathrm{Phi}=0.657$, $\mathrm{P}=0.000$ ). Trotter et al. and Stuart also found over $99 \%$ decline of $N$. meningitidis A in MenAfriVac ${ }^{\circledR}$ vaccinated countries $[15,25]$. As with this study, some authors found that after the introduction of MenAfriVac $\AA$, there was predominance of other meningitis pathogens ( $N$. meningitidis $\mathrm{W} 135, N$. meningitidis $\mathrm{C}, N$. meningitidis $\mathrm{X}$, and
Streptococcus pneumoniae) with the near disappearance of $N$. meningitidis A in African meningitis belt countries [12, 15, 19, 21].

\subsection{N. meningitidis A Epidemics Reported by Health Districts Before and After MenAfriVac ${ }^{\circledR}$ Introduction}

The study found $99.6 \%$ decline of risk for a health district to be in epidemic due to $N$. meningitidis A after the introduction of MenAfriVac ${ }^{\circledR}$, (RR 0.004 , 95\% CI 0.0010.016). This result confirmed findings of the literature characterized by a disappearance of $N$. meningitidis A epidemics in MenAfriVac ${ }^{\circledR}$ vaccinated health districts $[1,6$, $12,13,15,19,20,23-27,37]$. However, the risk for a health district to report $N$. meningitidis A epidemic after the introduction of MenAfriVac ${ }^{\circledR}$ was not found in the literature. Trotter et al. observed a 59\% decline globally in risk of a health district reaching meningitis epidemic threshold [15]. Stuart found that the number of all meningitis epidemics at health district level has fallen by $60 \%$ following MenAfriVac ${ }^{\circledR}$ vaccination; meningitis is caused by other meningococcal serogroups than A [25].

The results of the study confirmed those found in the literature. MenAfriVac ${ }^{\circledR}$ immunization campaigns implemented in 21 out of 26 African meningitis belt countries to protect individuals and communities have achieved one of the main objectives of the meningitis control program, to eliminate meningitis epidemics caused by $N$. meningitidis A. The results of this study show near elimination of $N$. meningitidis A epidemic with a $99.6 \%$ decline of risk for a health district to report $N$. meningitidis A epidemic. MenAfriVac ${ }^{\circledR}$ unvaccinated individuals and 
communities living in high-risk areas of $N$. meningitidis A epidemic are vulnerable. Therefore, prevention using MenAfriVac $\AA$ immunization was relevant to provide individual protection and herd immunity against $N$. meningitidis A.

\subsection{Limitations of the Study}

For a few countries, there were missing data. Fortunately, the missing data from countries were not significant at slightly under $2.5 \%$. The generalizability of this study is feasible due to the large sample size from the 21 countries chosen for this study out of 26 countries of the African meningitis belt.

\section{Conclusions}

In summary, the results of the study confirmed the finding of the literature. The study showed the effectiveness of introduction of MenAfriVac ${ }^{\circledR}$ in African meningitis belt. The key findings of the study indicated high degree of relationship between N. meningitidis A reported and the MenAfriVac ${ }^{\circledR}$ immunization in 21 out of the 26 countries of African meningitis belt between 2010 and 2017. The cases and epidemics of $N$. meningitidis $\mathrm{A}$ in African meningitis belt countries that vaccinated have declined significantly following the extensive roll-out of MenAfriVac ${ }^{\circledR}$. The findings showed that $N$. meningitidis A is being eliminated. The bacterial profile changed with the predominance of $N$. meningitidis $(\mathrm{C}, \mathrm{W} 135, \mathrm{X}, \mathrm{Y})$ and $S$. pneumoniae that have continued to cause epidemics.

The vaccination coverage obtained during campaigns were high and contributed to reducing $N$. meningitidis A cases and epidemics. This study showed that the achievement of high MenAfriVac ${ }^{\circledR}$ immunization coverage reduced $N$. meningitidis A cases and epidemics. The study demonstrated that high MenAfriVac ${ }^{\circledR}$ coverage and enhanced surveillance are pivotal to reduce the meningitis burden. Results will be used to inform policy and public health practice to reduce the meningitis cases and improve quality of live in the community.

Based on the existent gaps in the literature, relevant findings statistically significant provided by this study, few recommendations on practice and future studies were developed. Concerning research, to development and manufacture an affordable multivalent polysaccharide conjugate vaccine against $N$. meningitis $(\mathrm{A}, \mathrm{C}, \mathrm{W} 135, \mathrm{X}, \mathrm{Y})$ and introduce it in meningitis belt countries to eliminate meningococcal meningitis in Africa. About the practice, to update the risk assessment of the meningitis status of Africa meningitis belt after the introduction of MenAfriVac $\AA$, to continue improving meningitis enhanced surveillance in order to have accurate data and information on meningitis, and to improve public health policies on immunization and meningitis enhanced surveillance to ensure sustainable high immunization coverage of meningococcal vaccines and high quality of meningitis epidemic detection.

\section{Acknowledgements}

The author would like to thank my spouse Dr Gertrude Bita; Dr. German A. Gonzalez. and Dr. Namgyal L. Kyulo from Walden University; the Dean of the Faculty of Health and Pharmaceutical Sciences of Douala Prof. Albert Mouelle Sone; the Regional Director of WHO AFRO Dr. Matshidiso Moeti, the FRH/AFRO Director Dr. Felicitas ZAWAIRA, the IVE/WHO AFRO Coordinator Dr. Richard Mihigo; the WHO Representative of Madagascar Dr. Charlotte Faty Ndiaye; Dr. Marie-Pierre Presiozi WHO Geneva; Dr. Banche Anya and Dr Carol Tevi Benissan in WHO AFRO; Dr Ado Bwaka; Dr Amadou Fall; and Mr. Clement Lingani from WHO ISTWA; and Mr. Claude Bika. Their relevant guidance, advice and support are highly appreciated.

\section{References}

[1] World Health Organization. Meningococcal meningitis, https://www.whoint/en/news-room/factsheets/detail/meningococcal-meningitis; 2018 [assessed 23 March 2019].

[2] Centers for Disease Control and Prevention. An update on global partners reaching the ultimate goal of eliminating epidemic meningitis as a public health concern in Africa, http://www.cdc.gov/globalhealth/stories/meningitis.htm; 2015 [Accessed 1 May 2019].

[3] LaForce MF, Ravenscroft, N, Djingarey M, Viviani S. Epidemic meningitis due to Group A Neisseria meningitidis in the African meningitis belt: a persistent problem with an imminent solution. Vaccine 2009; 27 (S2), B13-19. https://doi:10.1016/j.vaccine.2009.04.062.

[4] Manigart O, Trotter C, Findlow H, Assefa A, Mihret W, Moti Demisse T, et al. Seroepidemiological study of serogroup A meningococcal infection in the African meningitis Belt. PLoS $\begin{array}{lllll}\text { One } & 2016 ; & 11 & \text { (2), } & \text { e0147928. }\end{array}$ https://doi:10.1371/journal.pone.0147928.

[5] Centers for Disease Control and Prevention. Working to eliminate epidemic meningitis in Sub-Saharan Africa, http://www.cdc.gov/ncird/div/DBD/newsletters/2012/summer/ mening.html; 2012 [accessed 4 May 2019].

[6] Greenwood B. Meningococcal meningitis in Africa. Transactions of the Royal Society of Tropical Medicine and Hygiene 1999; 93 (4), 341-353. https://doi:10.1016/S00359203(99)90106-2.

[7] Lapeyssonnie L. Cerebrospinal meningitis in Africa (in French), https://apps.who.int/iris/bitstream/handle/10665/72037/bulletin supp\%20_Vol28.pdf?sequence=1\&isAllowed=y; 1963[accessed 5 May 2019].

[8] Molesworth AM, Cuevas LE, Connor SJ, Morse AP, Thomson MC. Environmental risk and meningitis epidemics in Africa. Emerging Infectious Diseases 2003; 9 (10). https://doi:10.3201/eid0910.030182.

[9] Harrison LH, Trotter CL, Ramsay ME. Global epidemiology of meningococcal disease. Vaccine 2009); 27 (S2), B51-63. https://doi:10.1016/j.vaccine.2009.04.063. 
[10] Stephens DS, Greenwood B, Brandzaeg P. Epidemic meningitis, meningococcaemia, and Neisseria meningitidis. Lancet $2007 ; \quad 369 \quad$ (9580), 2196-2210. https://doi:10.1016/S0140-6736(07)61016-2

[11] World Health Organization. Global Health Observatory (GHO) data: Meningococcal meningitis, http://www.who.int/gho/epidemic_diseases/meningitis/en/201 9; [accessed 5 May 2019].

[12] World Health Organization. Introduction du vaccin antiméningococcique conjugué $\mathrm{A}$ au Burkina Faso, https://www.who.int/immunization/newsroom/events/menafri $\mathrm{vac} / \mathrm{fr} / ; 2010$ [accessed 4 May 2019].

[13] Aguado MT, Jodar L, Granoff D, Rabinovich R, Ceccarini $\mathrm{C}$, Perkin GW. From epidemic meningitis vaccines for Africa to the Meningitis Vaccine Project. Clinical Infectious Diseases 2015; 61 (S5), 391-395. https://doi:10.1093/cid/civ593.

[14] Frasch CE, Preziosi MP, LaForce FM. Development of a

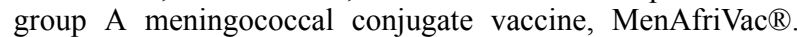
Human Vaccines \& Immunotherapeutics 2012; 8 (6), 715-724. https://doi:10.4161/hv.19619.

[15] Cibrelus L, Lingani C, Fernandez K, Perea WA, Hugonnet S. Risk assessment and meningococcal A conjugate vaccine Introduction in Africa: The district prioritization tool. Clinical Infectious Diseases 2015; $61 \quad$ (S5), S442-450. https://doi:10.1093/cid/civ671.

[16] Tiffay K, Jodar L, Kieny MP, Socquet M, Laforce M. The evolution of the Meningitis Vaccine Project. Clinical Infectious Diseases 2015; 61 (S5), S396-403. https://doi:10.1093/cid/civ594.

[17] Nicolas P. Meningococcal meningitis epidemics in subSaharan Africa and the meningococcal A conjugate vaccine. Médecine et Santé Tropicales 2012; 22 (3), 246-258. https://doi:10.1684/mst.2012. 0086.

[18] Centers for Disease Control and Prevention. Working to eliminate epidemic meningitis in Sub-Saharan Africa, http://www.cdc.gov/ncird/div/DBD/newsletters/2012/summer/ mening.html; 2012 [accessed 4 May 2019].

[19] Djingarey MH, Barry R, Bonkoungou M, Tiendrebeogo S, Sebgo R, Kandolo D, et al. Effectively introducing a new meningococcal A conjugate vaccine in Africa: The Burkina Faso experience. Vaccine 2012; 30 (S2): B40-45. https://doi:10. 016/j.vaccine.2011.12.073.

[20] Berlier M, Barry R, Shalid J, Sirica C, Brunier A, Hasan H, Bouma E. Communication challenges during the development and introduction of a new meningococcal vaccine in Africa. Clinical Infectious Diseases 2015; 61 (S5), S451-458. https://doi:10.1093/cid/civ493.

[21] Okwo-Bele JM, Laforce FM, Borrow R, Preziosi MP. Documenting the results of a successful partnership: A new meningococcal vaccine for Africa. Clinical Infectious Diseases 2015; 61 (S5), S349-390. https: //doi: $10.1093 /$ cid/civ592.

[22] Tiffay K, Jodar L, Kieny MP, Socquet M, Laforce M. The evolution of the Meningitis Vaccine Project. Clinical Infectious Diseases 2015; https://61 (S5), S396-403. doi:10.1093/cid/civ594.

[23] World Health Organization. Meningococcal vaccines: WHO position paper. Weekly Epidemiological Record 2011; 47 (86), $521-540$.

[24] Programme for Appropriate Technology Health \& World Health Organization. Meningitis A nearly eliminated in Africa through vaccination, http://www.who.int/lifecourse/news/meningitis-a-in-africa/en/; 2016 [accessed 5 May 2019].

[25] Novak RT, Kambou JL, Diomandé FVK, Tarbangdo TF, Ouédraogo-Traoré R, Sangaré L, et al. Serogroup A meningococcal conjugate vaccination in Burkina Faso: analysis of national surveillance data. Lancet Infectious Diseases 2012; 12, 757-764. https://doi:10.1016/s14733099(12)70168-8.

[26] Daugla DM, Gami JP, Gamougam K, Naibei N, Mbainadji L, Narbé $M$, et al. Effect of a serogroup A meningococcal conjugate vaccine (PsA-TT) on serogroup A meningococcal meningitis and carriage in Chad: A community study. Lancet 2013; 383 (9911), 40-47. https://doi:10.1016/S01406736(13)61612-8.

[27] Trotter CL, Lingani C, Katya F, Cooper LV, Bita A, TeviBenissan $C$, et al. The impact of MenAfriVac ${ }^{\circledR}$ in nine countries of the African meningitis belt, 2010-2015: An analysis of surveillance data. Lancet Infectious Disease 2017; 17, (S1473-3099) 30301-30308. https://doi:10.1016/S14733099(17)30301-8.

[28] Kristiansen PA, Diomandé F, Ky BA, Sanou I, Ouédraogo AS., Ouédraogo R, et al. Impact of the Serogroup A Meningococcal Conjugate Vaccine, MenAfriVac ${ }^{\circledR}$, on Carriage and Herd Immunity. Clinical Infectious Diseases 2013; 56 (3), 354-363. doi: 10.1093/cid/cis892.

[29] World Health Organization. Epidemic meningitis surveillance in the African meningitis belt. WHO guideline. World Health Organization 2014; WHO/HSE/PED/CED/14.1.1-12.

[30] Collard JM, Issaka B, Zaneidou M, Hugonnet S, Nicolas P, Taha MK., et al. Epidemiological changes in meningococcal meningitis in Niger from 2008 to 2011 and the impact of vaccination. BioMed Central Infectious Diseases 2013; 13, 576. https://doi:10.1186/1471-2334-13-576.

[31] Diallo AO, Soeters HE, Medah I, Ouédraogo-Traoré R, Sangaré L, Bicaba B, et al. Evaluation of meningococcal serogroup A conjugate vaccine impact on meningitis epidemics in Burkina Faso: A five-year (2011-2015) followup analysis. PLoS One 2017; 12 (11), e0187466. https://doi:10.1371/journal.pone.0187466.

[32] Diomandé FV, Djingarey MH, Daugla DM, Novak RT, Kristiansen PA, Collard JM, et al. Public health impact after the introduction of PsA-TT: The first 4 years. Clinical Infectious Diseases 2015; 61 (S5), S467-472. https://doi:10.1093/cid/civ499.

[33] LaForce FM, Djingarey M, Viviani S, Preziosi MP. Successful African introduction of a new Group A meningococcal conjugate vaccine: Future challenges and next steps. Vaccines \& Immunotherapeutics 2017; 14 (5), 1098-1102. https://doi:10.1080/21645515.2017.1378841.

[34] Lingani C, Bergeron-Caron C, Stuart JM, Fernandez K, Djingarey $\mathrm{MH}$, Ronveaux $\mathrm{O}$, et al. Meningococcal meningitis surveillance in the African meningitis belt, 2004-2013. Clinical Infectious Diseases 2015; 61 (S5), S410-415. https://doi:10.1093/cid/civ597. 
[35] Sambo L, Chan M, Davis S, Lake A, Berkley CP, Elias CJ. A vaccine meets its promise: success in controlling epidemic meningitis in Sub-Saharan Africa. Clinical Infectious Diseases 2015; 61 (S5), S387-388. https://doi:10.1093/cid/civ490.

[36] Stuart JM. Impact of serogroup A meningococcal conjugate vaccine for Africa. Human Vaccines \& Immunotherapeutics 2018; $14 \quad$ (5), $1116-1117$ https://doi:10.1080/21645515.2017.1412022.

[37] Obaro SK, Habib AG. Control of meningitis outbreaks in the African meningitis belt. Lancet Infectious Diseases 2016; 16 (4), 400-402. https://doi:10.1016/S1473-3099(16)00121-3.

[38] World Health Organization. Epidemic meningitis control in countries of the African meningitis belt, 2018. Weekly Epidemiological Record 2017; 14/15 (94), 169-188.

[39] Kristiansen PA. Impact the conjugate vaccine, MACV ${ }^{\circledR}$, on carriage of serogroup A Neisseria Meningitidis and disease transmission. Oslo, Norway: University of Oslo Library 2013.

[40] Kristiansen PA, Diomandé F, Ouédraogo R, Sanou I, Sangaré L, Ouédraogo AS, et al. Carriage of Neisseria lactamica in 1to 29-year-old people in Burkina Faso: epidemiology and molecular characterization. Journal of Clinic Microbiology 2012; 50 (12), 4020-4027. https://doi:10.1128/JCM.01717-12.

[41] Kristiansen PA, Jorgensen HJ, Caugant DA. Serogroup A meningococcal conjugate vaccines in Africa. Expert Review of Vaccines 2015; 14 (11), 1441-1458. https://doi:10.1586/14760584.2015.1084232.

[42] Fall A, Fouda Bita A, Lingani C, Djingarey M, Tevi-Benissan C, Preziosi MP, et al. Elimination of Epidemic Meningitis in the African Region: Progress and Challenges: 2010-2016. J Immunol Sci 2018; S (006): 41-45.

[43] LaForce FM, Okwo-Bele JM. Eliminating Epidemic Group A meningococcal meningitis in Africa through a new vacci.
[44] MenAfriCar Consortium. The diversity of meningococcal carriage across the African meningitis belt and the impact of vaccination with a group A meningococcal conjugate vaccine. Journal of Infectious Diseases 2015; 212 (8), 1298-1307. https://doi:10.1093/infdis/jiv211.

[45] Mueller JE. Conjugate vaccine introduction in the African meningitis belt: meeting surveillance objectives. Tropical Medicine \& International Health 2013; 18 (1), 58-64. https://doi:10.1111/tmi.12009.

[46] Centers for Disease Control and Prevention. Principles of epidemiology in public health practice (3rd ed). Atlanta, GA: U. S. Department of Health and Human Services, Centers for Disease Control and Prevention, Office of Workforce and Career Development 2012.

[47] World Health Organization, Centers for Disease Control and Prevention. Technical guidelines for integrated disease surveillance and response in the African region (2nd ed. ). Brazzaville, Republic of Congo: World Health Organization 2010.

[48] Standard operating procedures for enhanced meningitis surveillance in Africa, https://apps.who.int/iris/bitstream/handle/10665/312141/9789 290234241-eng. pdf; 2019 [accessed 5 May 2019].

[49] Carod AFJ. Meningococcal meningitis: vaccination outbreak response and epidemiological changes in the African meningitis belt. International Health 2015; 7 (4): 226-227. https: //doi: 10.1093/inthealth/ihv025.

[50] Djingarey MH, Diomandé FV, Barry R, Kandolo D, Shirehwa $\mathrm{F}$, Lingani $\mathrm{C}$, et al. Introduction and Rollout of a New Group A Meningococcal Conjugate Vaccine (PsA-TT) in African Meningitis Belt Countries, 2010-2014. Clinical Infectious Diseases 2015; 6: 5 434-441. https://doi.org/10.1093/cid/civ551. 